\title{
SIGNIFICADO Y FUNCIÓN DEL DERECHO DE SUFRAGIO EN LA ACTIVIDAD ELECTORAL DE UN ESTADO DEMOCRÁTICO
}

José Luis López González Montserrat de Santiago

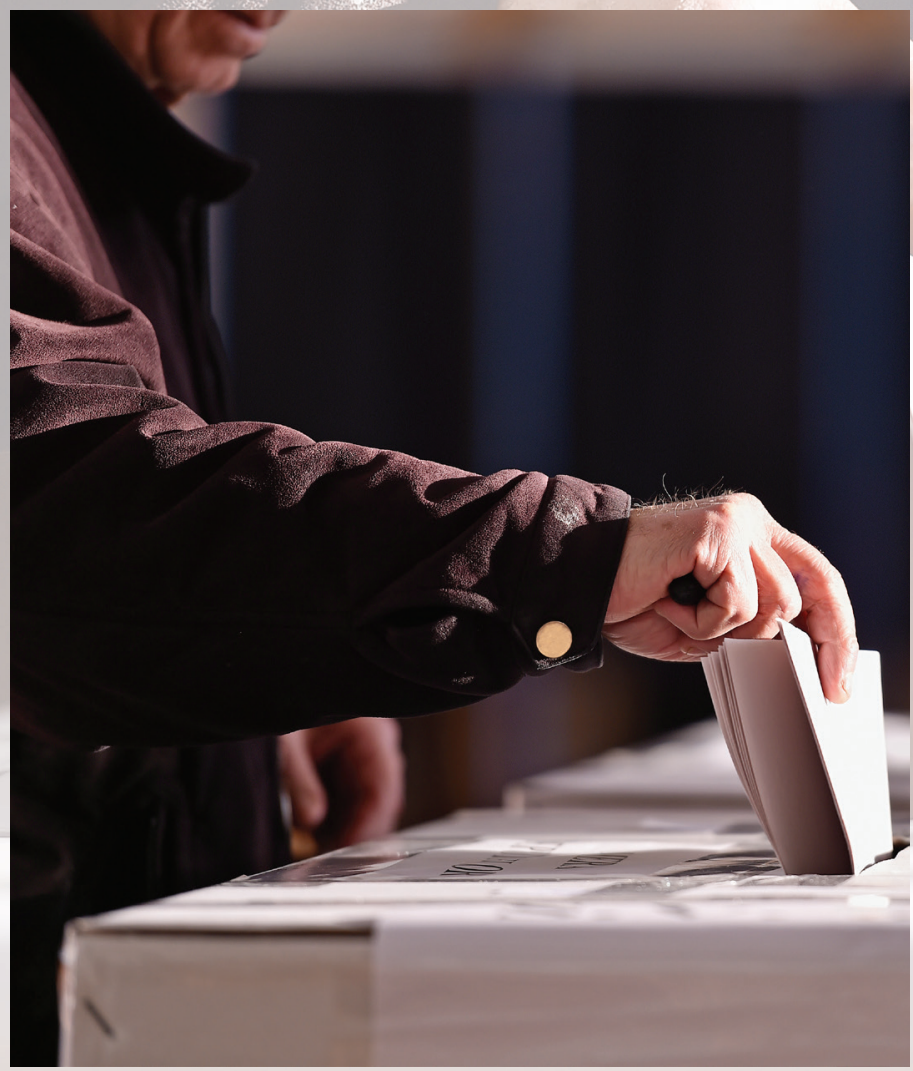





\title{
SIGNIFICADO Y FUNCIÓN DEL DERECHO DE SUFRAGIO EN LA ACTIVIDAD ELECTORAL DE UN ESTADO DEMOCRÁTICO
}

\author{
JosÉ LuIS LÓPEZ GONZÁLEZ \\ Montserrat de SAntiago \\ Universidad Autónoma de Madrid
}

\section{Resumen}

La investigación se encuadra en el derecho electoral, como sector del derecho constitucional. El derecho de sufragio es un elemento arquitectural básico de la cláusula constitucional de Estado democrático. Es un derecho subjetivo y también una pieza clave del Estado democrático, en la medida en que, sin elecciones y sin derecho de sufragio, no es posible la renovación y la continuidad del sistema institucional sobre el que descansa una democracia. A lo anterior ha de añadirse que la participación mediante referendo constituye actividad electoral que tiene como presupuesto el reconocimiento y la protección jurisdiccional del derecho de sufragio. ${ }^{1}$

Palabras clave: derecho de sufragio, mandato representativo, sufragio activo, sufragio pasivo, referendo.

Los autores: José Luis López González, profesor titular de Derecho Constitucional de la Universidad Autónoma de Madrid, miembro de la Asociación de Constitucionalistas de España (ACE), codirector del Seminario de Derecho Deportivo de la Facultad de Derecho de la Universidad Autónoma de Madrid, socio fundador del Club Profesional Iustel. Correo electrónico: josel.lopez@uam.es

Montserrat de Santiago, gestora procesal en juzgados de la comunidad de Madrid, investigadora del grupo de investigación multidisciplinar Cultura, imaginario y creación artística-UAM. Correo electrónico: mds49@madrid.org

Recibido: 17 de agosto de 2017; evaluado: 22 de septiembre de 2017; aceptado: 1 de octubre de 2017.

\footnotetext{
Este trabajo toma como punto de partida una investigación inicial llevada a cabo para la defensa del TFG realizada por la coautora y dirigida por el profesor, doctor José Luis López González.
} 


\title{
MEANING AND ROLE OF VOTING RIGHTS IN A DEMOCRATIC STATE'S ELECTORAL ACTIVITY
}

\author{
JosÉ LuIS LÓpez GONZÁLEZ \\ Montserrat de Santiago \\ Universidad Autónoma de Madrid
}

\begin{abstract}
The research falls within the theoretical framework of Electoral Law, as an area of knowledge of Constitutional Law. The right to vote is a basic architectural element of the constitutional clause of a Democratic State.

The right to vote is a subjective right, but it is also a key part in the context of that Democratic State clause, insofar as, without elections - and therefore without the right to vote-there is no room for renovation and the resulting continuity of the institutional system on which Democracy lies. Moreover, participation by means of a referendum is also electoral activity which grants recognition and jurisdictional protection to the right to vote.
\end{abstract}

Keywords: Mandate representative, Right to vote, Active Suffrage, Passive suffrage, Referendum vote.

About the authors: José Luis López González, associate professor of Constitutional Law from Universidad Autónoma de Madrid, member of the Association of Spanish Constitutionalists (ACE), co-director of the Sports Law Seminar from the School of Law of Universidad Autónoma de Madrid, founding partner of the Club Profesional Iustel.E-mail: josel.lopez@uam.es

Montserrat de Santiago, case manager in different courts of the community of Madrid, researcher for the multidisciplinary research group, "Cultura, imaginario y creación artística" from Universidad Autónoma de Madrid. E-mail: mds49@madrid.org

Received: August 17,2017; evaluated: September 22, 2017; accepted: October 1, 2017 
La democracia depende de ciudadanos informados y no de masas apáticas sumidas en la oscuridad por sus gobernantes bien o mal intencionados

Konrad Hesse

\section{Introducción}

El concepto de democracia vive momentos difíciles que tienen que ver con las malas prácticas, la corrupción y el condicionamiento de la decisión pública por fuerzas incontroladas que obedecen al nuevo orden (o, más bien, desorden) económico global. De manera gráfica y deliberadamente exagerada, una vez perdida su verdadera libertad de decidir, los políticos tienden a asemejarse a lo que serían meras marionetas movidas por su propia vanidad. De algún modo, los Gobiernos democráticos de Occidente "escriben sus leyes al dictado". En efecto, para hablar de democracia y de elecciones libres se necesitan opciones políticas identificables como tales (el pluralismo ha sido reducido de manera violenta por las consecuencias económicas de la globalización) y candidatos que representen opciones ideológicas diferenciadas. Las elecciones suponen, si se nos permite la simpleza, posibilidad de elegir entre alternativas ciertas.

Los casos de corrupción que proliferan por doquier y las dificultades de los partidos políticos para dar cumplimiento al mandato constitucional de estructura interna y funcionamiento democrático, así como la oscuridad en su financiación, completan un panorama donde se multiplican las dudas y se difuminan las que otrora fueron certezas.

Todo ello se traduce en una realidad: los ciudadanos no estamos contentos con la ejecutoria de los poderes públicos y nuestra principal herramienta para invertir este panorama tan desolador, por más que en demasiadas ocasiones no se aprecie así, consiste en ejercer el derecho fundamental de todos los ciudadanos del mundo: el derecho de sufragio o de voto.

El objeto principal del presente estudio es abordar, en sus perfiles generales básicos, la compleja problemática de este derecho que presenta dos vertientes diferenciadas, a la par que conectadas: la subjetiva (se trata de un derecho de ejercicio individual e indelegable) y la objetiva (es algo más que un derecho subjetivo, por su enorme relevancia práctica como instrumento decisivo en la continuidad del sistema 
institucional previsto en nuestra norma suprema y en los textos constitucionales de otros países, en los que incluso se ha instaurado la obligación del voto).

El elemento esencial a la hora de afrontar los problemas del derecho de sufragio no es otro que la existencia de un régimen de opinión pública libre. Dicho régimen implica, desde luego, la existencia de prensa libre y de ciudadanos con una mínima formación en principios y valores constitucionales que les permitan tomar conciencia del sentido y de la trascendencia que encierra el ejercicio del derecho de sufragio o voto.

Tampoco cabe obviar, aunque no constituya el objeto central de este trabajo, el contenido politológico implícito en el "entorno" del derecho fundamental que aquí se estudia, integrado por asuntos que aparecen en la escena política: nos referimos a conceptos tan familiares para un ciudadano informado como los de corrupción, desafección de la ciudadanía o crisis de los partidos "convencionales".

\section{Democracia representativa}

La democracia que proponía Rousseau en su discurso en el Contrato social fracasó porque se basaba en el poder de la voluntad popular como expresión de la voluntad general. Por lo tanto, rechazaba como principio la representación, pues la soberanía no podía ser representada. En su apartado sobre las votaciones, identificaba la voluntad del pueblo con la de todos sus integrantes, aunque también sostenía que la esencia de tal voluntad general es la de la mayoría. Es decir, no reparó en que "un gobierno que no resulte instaurado de un proceso donde se haya plasmado la voluntad popular, no puede considerarse un verdadero gobierno". ${ }^{2}$

Pongamos como ejemplo la Constitución española: el Artículo 66 proclama que las Cortes generales, integradas por el Congreso de los Diputados y el Senado, representan al pueblo español, ejercen la potestad legislativa del Estado, aprueban sus presupuestos y controlan la acción del Gobierno. No en vano el Parlamento ostenta la supremacía institucional en tanto depositario orgánico de la decisión del pueblo cuando se pronuncia en las correspondientes elecciones.

2 Edgar Herrera Loaiza y Enrique Villalobos Quirós, "Sufragio y principio democrático: consideraciones sobre su existencia y vinculancia", Revista de Derecho Electoral, núm. 1 (2006): 2. 
En consonancia con lo anterior, el profesor Aragón recuerda: "La democracia parlamentaria es la forma común en los Estados auténticamente democráticos". ${ }^{3}$

El Parlamento aprueba normas (incluidos los presupuestos generales del Estado en cada anualidad, que constituyen el programa económico del Gobierno y guardan una relación directa con las previsiones del programa electoral que obtuvo el respaldo mayoritario de los votantes), procede a la investidura del nuevo presidente del Gobierno producto de las elecciones y lidera el seguimiento, el control y la crítica de la labor del Gobierno.

A diferencia de lo que ocurre en otros países de la Unión Europea, en este sistema de parlamentarismo bicameral, el presidente del Gobierno aglutina un conjunto de facultades y poderes muy amplio y decisivo para el devenir político e institucional de la Nación. De hecho, son los partidos políticos y los acuerdos entre ellos los que fundamentan la vida política española.

Para entender el presente debemos reconocer algunas bases del pasado. En 1748 se publicó De l'esprit des lois. ${ }^{4}$ En esta célebre obra se afirmaba que la ventaja de los representantes era su capacidad para debatir las propuestas. La inhabilidad del pueblo para ello supondría un hándicap grave para la democracia, puesto que debería limitar su participación política a la elección de sus representantes.

Antes de continuar, cabe hacer referencia a las modalidades de participación política con actividad electoral, a saber:

Figura 1. Tipos de representación

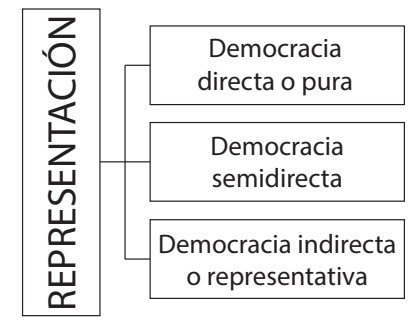

Fuente: elaboración propia

Manuel Aragón Reyes, "Democracia y Parlamento", Revista Catalana de Dret Públic, núm. 37, (2008): 131.

4 Charles Louis de Secondat es más conocido como barón de Montesquieu. Charles Montesquieu, Del espíritu de las leyes (Madrid: Tecnos, 2007). 
La democracia parlamentaria y la democracia constitucional que tiene que ser representativa pueden concebirse de formas diferentes, pero giran en torno a un núcleo invariable. Como en su momento escribió Kelsen, ${ }^{5}$ solo la democracia puede ser parlamentaria. Entonces, cabe preguntarse iqué democracia tiene el Parlamento? ¿Qué función tiene y cómo se legisla? Si se retomara la lectura de una de sus grandes obras, se empatizaría con términos como transfuguismo, educación para la democracia, obstrucción parlamentaria, populismos, etc.

a) Democracia directa o pura: es el propio pueblo el que debate y aprueba las leyes, sin mandatarios ni representantes. Se presentó en algunas polis griegas $y$, en la actualidad, en algunos cantones suizos. Tiene el inconveniente de que necesita una extensión territorial y densidad de población compatible con la eventualidad de consulta y la decisión de la comunidad en cada asunto referente a su Gobierno, por lo que resulta difícil.

b) Democracia semidirecta: el pueblo puede participar en el proceso de formulación de las disposiciones del poder en el Estado. Concierta la idea de la democracia directa con la representativa sin sustituirla, pero se verifica el requisito de participación directa en la toma de las decisiones políticas. Comprende varias formas:

- El referendo: derecho del pueblo a participar en las consultas que se convoquen.

- La iniciativa popular: se habilita a una parte del cuerpo electoral para que presente un proyecto de ley tratado por las asambleas legislativas (iniciativa formulada) o exija la consulta popular sobre cuestiones legislativas determinadas (iniciativa simple).

- Plebiscito: excepcional y extraordinariamente, el cuerpo electoral puede intervenir en la ratificación de un acto político de naturaleza constitucional o gubernamental.

- Revocación popular recall: una parte del cuerpo electoral puede pedir la destitución o separación de aquellos representantes que han dejado de merecer su confianza.

Hans Kelsen, Esencia y valor de la democracia (Oviedo: KRK, 2006), 153 y ss. 
- Apelación de sentencia "variante del recall": aplicable a las decisiones judiciales que declaren la inconstitucionalidad de una ley, es decir, el derecho del cuerpo electoral a ejercer el control sobre la constitucionalidad de las leyes.

c) Democracia indirecta o representativa: se define como la participación en la adopción de decisiones que versen sobre asuntos de interés público por medio de representantes libremente elegidos. El pueblo no gobierna ni delibera, pero designa a quienes hayan de hacerlo en su representación. Por un lado, Mill habló sobre la tiranía de la mayoría e hizo hincapié en la participación de la minoría. Era un defensor de la democracia representativa, en la que todos los ciudadanos debían estar representados; por ende, la opinión de esa minoría debería contar tanto o más que la de la mayoría, por su singularidad. Mill fue constante en la defensa de un espacio para disidentes que se situaría en los márgenes del statu quo. ${ }^{6}$

Por otro lado, Locke establecía que "Cada hombre que consiente en reunirse con otros y formar un cuerpo político bajo un gobierno se pone a sí mismo bajo obligación ante todos los miembros de esa sociedad de someterse a la determinación y resoluciones de la mayoría". ${ }^{7}$

Conviene no olvidar que la democracia solo es posible con libertad de discusión y crítica mediante el debate entre las opciones programáticas y los equipos políticos. En todo caso, es indudable que la capacidad de la ciudadanía para criticar a sus gobernantes requiere de la transparencia y publicidad de su gestión.

En efecto, comprobamos que el sistema de Gobierno parlamentario está basado en la confianza y exigencia de responsabilidad política por parte de las Cortes al Gobierno. Controlar la acción del Gobierno es una de las principales funciones del Parlamento en el Estado constitucional, precisamente porque ese tipo de Estado no solo se basa en la división de poderes, sino también en el equilibrio entre ellos, esto es, en la existencia de controles recíprocos, frenos y contrapesos que impidan el ejercicio ilimitado e irresponsable de las actividades públicas. El parlamentario se configura, pues, como un control político, cuyo agente es el Parlamento y su objeto es la acción del Gobierno y, por extensión, la de cualquier entidad pública.

\footnotetext{
John Stuart Mill, Consideraciones del gobierno representativo (Madrid: Alianza, 2016), 90 y ss. John Locke, Dos ensayos sobre el gobierno civil (Madrid: Espasa Calpe, 1997), 274.
} 
Se exceptúan las incluidas en la esfera del poder Judicial, pues, por principio, este debe gozar de completa independencia respecto a los demás poderes del Estado. ${ }^{8}$ Cualquier sistema democrático podrá elegir al Gobierno, el cual debe tomar las decisiones, que deberán ser evaluadas.

\subsection{El mandato representativo}

El mandato representativo surgió en Inglaterra, ante la insatisfacción que generaba el mandato imperativo. Algunos autores observan que, como resultado de esa evolución, se originó una representación de la comunidad o del pueblo, no de sectores. El representante ostentaba una competencia universal; en consecuencia, no podía ser cesado mediante retirada o cancelación del poder (que no existía) ni se le podía exigir responsabilidad por el incumplimiento de las instrucciones (porque no las había). Su única sanción era la no reelección una vez finalizara su mandato. Las asambleas se integraban con dichos representantes, en órganos colegiados que actuaban en nombre de la comunidad. La duración de los mandatos estaba fijada por la ley, ${ }^{9}$ es decir, ningún Estado democrático podía renunciar a la representación. Para Aragón Reyes y López González, "el mandato se configura como un instrumento institucionalizado cuya finalidad se orienta a la participación indirecta de los ciudadanos en los asuntos públicos". ${ }^{10}$

El parlamentario representa a toda la Nación. Su elección es por mandato representativo en España, así como en Europa, excepto en Suiza. Ese mandato no es revocable, pero el elector puede no votar para su reelección. Aunque el partido incluye al candidato en la lista electoral, ello no significa que deba seguir las instrucciones de dicha fuerza política. Entre el representante elegido y el representado se establece una relación basada en el mandato libre, puesto que el Artículo 67.2 prohíbe expresamente el mandato imperativo para los miembros de las Cortes generales,

8 Aragón Reyes, "Democracia y Parlamento", 129 y ss. En cualquier caso, "conviene que el ciudadano ejerza su derecho de sufragio del modo más consciente y documentado posible. La condición de ciudadano democrático exige un esfuerzo por obtener información y un compromiso para las autoridades de facilitarla (transparencia en la gestión pública)". José Luis López González, "Lo jurídico y lo político en la respuesta a la crisis institucional: mejora de los instrumentos de supervisión y control y pacto político por el Estado social", Revista Gaceta Sindical. Reflexión y Debate. núm. 23 (2014): 234.

9 Manuel Martínez Sospedra, Joaquín Marco Marco y Ainhoa Uribe Otarola, Sistemas electorales. Un estudio comparado (Valencia: Tirant lo Blanch, 2007), 26 y ss.

10 Manuel Aragón Reyes y José Luis López González, "Revocatoria de mandato" en Diccionario electoral (San José: Instituto Interamericano de Derechos Humanos, 2000), 1141. 
limitación extensible a los demás órganos representativos; de ese modo, una vez electo, no solo representa a quienes lo eligieron, sino a todo el cuerpo electoral. ${ }^{11}$

Los fines esenciales de la representación se podrían resumir en cuatro: ${ }^{12}$

- Consagrar la legitimidad de los gobernantes como titulares de un justo título de mando.

- Dar expresión a la voluntad de un colectivo, es decir, la voluntad popular en un momento determinado.

- Obtener una imagen de la opinión; lo que importa es detallar las opiniones que tienen respaldo significativo entre los ciudadanos.

- Establecer un Gobierno determinado. Un medio orientado a la designación de un gobernante o equipo de Gobierno o a la determinación de una mayoría parlamentaria capaz de formar uno; en suma, tener una mayoría gobernable y gobernante.

En consecuencia, el mandato representativo se atribuye a cada mandatario. Sin embargo, los agentes principales de las Cámaras no son los parlamentarios, sino los partidos políticos y el Parlamento es el comité legislativo del Gobierno.

El distanciamiento entre representantes y electores y la inconsistencia de la vida parlamentaria, que propicia el protagonismo de los jueces y de los medios, demuestran que la práctica política deba ser transformada. ${ }^{13}$

No debe olvidarse que, además de producir representación por la voluntad popular, cualquier proceso electoral debe servir a los ciudadanos para expresar sus preferencias políticas para que sean valoradas por los representantes elegidos. Como fácilmente cabe constatar, la práctica política viciada por unos partidos burocratizados y en exceso alejados del ciudadano ha ocasionado una notable merma de la función de control del Parlamento.

\footnotetext{
Aragón Reyes y López González, "Revocatoria de mandato", 1141 y ss.

Martínez Sospedra, Marco Marco y Uribe Otarola, Sistemas electorales, 26.

Aragón Reyes, "Democracia y Parlamento", 131 y ss.
} 


\subsection{Derecho electoral y proceso electoral}

En el régimen electoral se pone de manifiesto el derecho fundamental de participación, orientado a la creación de representación política. El procedimiento electoral comprende desde la formación del censo hasta la proclamación de resultados, el cual sienta las bases de la propia democracia. Para García Soriano:

El Derecho Electoral se constituye alrededor de un objeto original que son las elecciones. Las necesidades inherentes al mismo le confieren características específicas y exigen la adopción de soluciones y técnicas particulares que el propio derecho electoral ha ido desarrollando con el fin de dar la respuesta adecuada a los problemas que se han venido planteando. ${ }^{14}$

Unos principios del derecho electoral son obvios, como el de igualdad y el de neutralidad. Entre las fuentes del derecho electoral han de mencionarse la Constitución como marco y norma fundamental, las leyes electorales autonómicas y otras leyes. Algunas fuentes del derecho electoral proceden de la normativa de producción europea, la jurisprudencia, los acuerdos y las instrucciones de la Junta Electoral y las disposiciones con rango reglamentario.

En ausencia de poderes efectivos, el riesgo es que el político prescinda —o se vea obligado a hacerlo_- del poder que se le supone en tanto representante popular y se convierta en marioneta movida por su propia vanidad. En este sentido, las deudas de los partidos condicionan el crédito electoral y derivan en un trato privilegiado a entidades financieras. A ello ha de añadirse el dominio de los consejos de administración de las empresas de comunicación por multinacionales y entidades financieras (las famosas puertas giratorias). Este estado de cosas se completa con la aparición de medios de comunicación "de partido", a lo que se suma el juicio de la decisión popular, producto del libre ejercicio del derecho de sufragio, por parte de los agentes económicos con reflejo directo en las sesiones de Bolsa.

El acceso a un cargo público representativo debe producirse en escenarios de igualdad; tal igualdad deberá concretarse en un sistema electoral equilibrado, capaz de generar una adecuada traducción de votos de los electores en escaños en el Parlamento.

14 María Victoria García Soriano, Elementos de derecho electoral (Valencia: Tirant lo Blanch, 2010), 25. 
El verdadero problema del que adolece el sistema representativo no procede tanto del carácter cerrado y bloqueado de las listas electorales cuanto de la deficiente selección de las élites por parte de los propios partidos políticos. Esta última circunstancia, lejos de aliviar el problema, incrementa su gravedad.

En un Estado constitucional, el proceso electoral:

Es el instrumento normal y principal para producir representación, situación que se produce con mayor motivo si dicho Estado, es además, democrático. Pero no se puede perder de vista que la elección no agota la representación y que esta última es un fenómeno que va más allá de aquélla. ${ }^{15}$

Las fases del procedimiento electoral son:

- Convocatoria de elecciones a las Cortes generales.

- Nombramiento de representantes y administradores y de las candidaturas.

- Presentación y la proclamación de los candidatos.

- Campaña electoral.

- Jornada electoral o fecha prevista para la celebración de los comicios.

- Recuento de los votos y su translación en escaños.

- Proclamación de los resultados y del candidato o de los candidatos ganadores.

\section{El concepto de sufragio}

El sufragio es un elemento esencial en los Estados democráticos, aunque tiene las restricciones de las leyes o normas que lo garantizan. En la actualidad, el sufragio es equiparable al significado de elecciones. Es, sin duda, una garantía para la elección de los gobernantes, en igualdad de condiciones. Ha de tenerse muy presente que la consulta al pueblo no supone la delegación en el mismo de la competencia

15 Martínez Sospedra, Marco Marco y Uribe Otarola, Sistemas electorales, 27. 
que, en realidad, tiene el órgano decisorio del Estado que corresponda; prueba de ello es el carácter facultativo de la propia convocatoria de la consulta.

El pueblo no sustituye al poder público, sino que se introduce en el procedimiento consultivo en el segundo lugar. En este sentido, consultivo no es sinónimo de no vinculante, sino de no ratificador o sancionador. Lo que sí parece difícilmente discutible, más allá de cualquier regulación normativa, es que el resultado del referendo nacional siempre debería ser vinculante. ${ }^{16}$

La palabra "sufragio" procede etimológicamente de la voz latina suffragium, que significa apoyo o auxilio y se define como: "Sistema electoral para la provisión de cargos. Voto de quien tiene capacidad de elegir". ${ }^{17}$ Dicho voto puede ser restringido (se reserva su ejercicio para los ciudadanos que reúnen ciertas condiciones) o universal (tienen derecho a participar todos los ciudadanos, salvo determinadas excepciones). Al contrario de lo que se pueda pensar:

El sufragio, cualquiera que sea su modalidad o periodicidad con que se ejerza, es un derecho y un deber subjetivo y objetivo que se inserta dentro de los derechos políticos de los hombres y es el medio o instrumento apreciable cuantitativamente, que tiene el nacional de un Estado capaz de realizar actos políticos, para participar en la vida pública de su país. ${ }^{18}$

El sufragio se puede entender de dos formas: i) en sentido amplio, que hace alusión al derecho por el cual un ciudadano participa activamente en la formación de la voluntad de la comunidad social, y ii) en sentido estricto o restringido, que es el acto mediante el que el ciudadano exterioriza, con su voto, su preferencia política. ${ }^{19}$

No obstante, en un Estado constitucional democrático, la representación popular no es absoluta, tiene sus límites, esto es, las elecciones no legitiman todos los actos del poder. En todo caso, los ganadores en las elecciones no tienen un poder ilimitado; por el contrario, han de respetar la Constitución, someterse al control político ejercido por el Parlamento y al jurídico a cargo del poder Judicial. No debe olvidarse, además, que se trata de titulares ocasionales del poder que han de

16 López González, José Luis. "El referéndum nacional consultivo sobre decisiones políticas de especial trascendencia en el ordenamiento constitucional español”. Revista de Derecho Político, núm. 65 (2006): 245.

17 Real academia de la lengua española. "Sufragio" en Diccionario de la Real Academia Española. http://dle.rae. es/?id=YfDjp3l (acceso diciembre 12, 2016).

18 Hugo Tagle Martínez, "El derecho de sufragio o el sufragio ante el derecho", Revista Chilena de derecho 6, núm. 1-4 (1979): 266.

19 Martínez Sospedra, Marco Marco y Uribe Otarola, Sistemas electorales, 31 y ss. 
rendir cuentas en la próxima convocatoria electoral, en la cual los electores deberán evaluar de nuevo tanto la labor del Gobierno como la de la oposición a la hora de emitir de nuevo su voto.

La limitación material del poder consiste, ante todo, en que los poderes constituidos estén supeditados a las normas. Además, el Estado no puede transgredir los derechos fundamentales, que hoy constituyen una especie de derecho común de todos los países con un sistema constitucional democrático.

Los investigadores más relevantes en derecho electoral definen el término sufragio como análogo a votar o elegir, como un derecho constitucional y político, que legitima políticamente a un Gobierno democrático. Incluso se puede ejercer el derecho de la abstención; por eso, el voto es "una manifestación de un pensamiento político y, por este motivo, el proceso electoral se dirigirá a obligar a los electores a formarlo y manifestarlo". ${ }^{20}$

\subsection{El sufragio como derecho, deber y función}

Según Kelsen, ${ }^{21}$ el sufragio permite al ciudadano titular de ese derecho, sea activo o pasivo, formar parte de la voluntad del Estado por medio del mecanismo de la producción de las normas por voluntad objetiva, es decir, mediante la participación del pueblo. "Sin sufragio no puede haber democracia, y esto es así porque la democracia es el poder del pueblo delegado, por lo que a este corresponde su debido ejercicio y protección, de la mano también con un Estado responsable". 22 Por ende, es un elemento ineludible en la participación política; no puede ser sustituido y ha de ser universal, libre, secreto, directo e igual para todos y se debe ejercer sin coacciones ni mediación alguna.

Es necesario diferenciar entre los votantes y los electores. Estos últimos pueden ejercer o no su derecho al voto si cumplen los requisitos y se encuentran inscritos en el censo electoral. El votante es el elector que ha ejercido su derecho al depositar su voto en la urna.

Se trata de una obligación ética al margen de la regulación jurídica que en modo alguno sanciona la abstención. En la campaña institucional ni tan siquiera se puede

\footnotetext{
Martínez Sospedra, Marco Marco y Uribe Otarola, Sistemas electorales, 30.

21 Hans Kelsen, Teoría general del Estado (Ciudad de México: Ediciones Coyoacán, 2008), 333 y ss.

22 Herrera Loaiza y Villalobos Quirós, "Sufragio y principio democrático", 20.
} 
promover la participación; solo se informa la fecha de celebración de las elecciones y de la posibilidad de ejercer el derecho de sufragio por correo.

Varios elementos esenciales presiden el derecho de sufragio en España:

- Se debe ejercer en libertad, esto es, sin amenazas o coacciones que afecten la libertad individual del votante.

— Pueden votar los mayores de 18 años capacitados (art. 12 CE).

- Tienen capacidad para ejercer el derecho de sufragio activo los no incapacitados o internados en centros psiquiátricos por sentencia firme.

- Pueden sufragar los connacionales españoles. Los residentes extranjeros solo pueden ser titulares de ese derecho en las condiciones del Artículo 13.2 CE, esto es, en elecciones locales, en régimen de reciprocidad.

La edad y la capacidad son las restricciones objetivas negativas clásicas, junto con la calidad de condenado. Al especificarlas en las leyes, se intenta asegurar que todos aquellos que ejerzan su derecho estén capacitados para hacerlo. Por ser un derecho cuyo ejercicio es directo, no cabe representación por parte de tutores o guardas de los menores de edad o incapaces.

Como se ha analizado, conforme establece el Artículo 1.2 CE, en las democracias actuales el poder emana del pueblo y lo ejercen sus representantes, electos por los ciudadanos mediante su derecho al sufragio (universal, directo, libre, secreto, sin coacción, etc.). Hay tres funciones políticas que hacen posible el derecho a la participación electoral: i) elegir representantes parlamentarios en un proceso electoral; ii) conformar Gobiernos plurales y diversos, y iii) legitimar mediante el voto de los ciudadanos, para poder ser gobernados por sus representantes, en la medida en que poseen justo título para el ejercicio de su cargo. Por todos estos planteamientos, hay una alta correlación: cuanto mayor sea la participación electoral, mayor legitimidad para los representantes. Los procesos de participación:

[...] a nivel mundial, suponen una prueba de stress continua para los ideales democráticos de gobierno. Es por ello que resulta cabal estudiar los mecanismos que influyen positiva o negativamente en el aumento 
de los índices de participación, baremo de la calidad de la democracia representativa. ${ }^{23}$

\subsection{Modalidades de sufragio}

Como características generales, debe ser universal, es decir, se concede a todo ciudadano, sin discriminación económica, religiosa por sexo o por raza, aunque puede limitarse por capacidad y edad (en España, 18 años). Se ejerce personalmente —o por correo, en el caso español—. Debe ser libre, sin coacciones. Cada voto tiene el mismo valor, pero no hay que confundirlo con lo que puede valer dentro del resultado del proceso electoral. Deberá ser directo y dejar en manos del cuerpo electoral la elección de sus candidatos. Es secreto, como garantía de libertad y no es corrupto: su compra no es ética. Para siempre quedarán como ejemplo los votos comprados por el presidente Lincoln, de Estados Unidos; eso sí, para una causa justa como era la abolición de la esclavitud. "La minoría se contaría solamente como número por el voto; pero como poder moral pesaría mucho más a virtud de su saber y la influencia que tal conocimiento le reportaría." ${ }^{24}$

Corresponde ahora proceder a examinar las modalidades del derecho de sufragio:

Figura 2. Tipos de sufragio

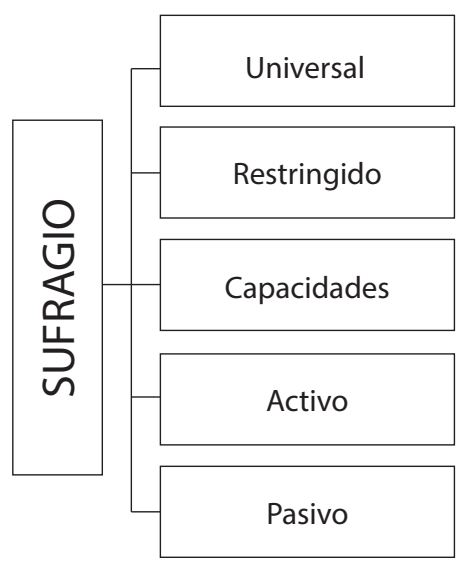

Fuente: elaboración propia

23 Angélica Mendieta Ramírez, Enrique González Vallés y David Caldevilla Domínguez, "Pros y contras del voto obligatorio en la formación de la cultura política colectiva: electopartidismo", Perspectivas de la Comunicación 8, núm. 2 (2015): 186.

24 Mill, Consideraciones del Gobierno representativo, 94 y ss. 


\subsubsection{Sufragio universal}

El carácter universal del sufragio garantiza su pleno ejercicio al margen de circunstancias como sexo, raza, religión, creencias o situación económica, es decir, una persona, en pleno ejercicio de sus derechos civiles y políticos, un voto. Cabe hablar de sufragio universal en aquellos casos:

[...] en los que el nacional es, en principio, titular del derecho, y las condiciones de capacidad exigidas son las mismas, o las más próximas posibles, a aquéllas que determinan la capacidad general de obrar, de tal modo que la plenitud de los derechos civiles conlleve la titularidad y capacidad de ejercer el derecho de sufragio. ${ }^{25}$

\subsubsection{Sufragio restringido}

También se le conoce como sufragio censitario y surgió para delimitar el poder político que la burguesía le arrebató a la aristocracia feudal. Su uso fue generalizado en Europa en el siglo XIX y perduró en muchos países hasta mediados del siglo XX. Supedita la titularidad del derecho de sufragio al cumplimiento de ciertas condiciones de propiedad. Benjamín Constant fue defensor de este derecho, pues, en su opinión, la propiedad posibilita el ocio, da luces, proporciona rectitud de juicio y da lugar a hombres capaces del ejercicio político. ${ }^{26}$ Se trata, en definitiva, de un sufragio incompatible con el principio democrático.

El sufragio restringido solo pueden ejercerlo algunos individuos con determinados elementos, como riqueza o estatus social.

\subsubsection{Sufragio de capacidades}

Correspondía a quienes no eran analfabetos, es decir, a aquellos que, aunque no tenían fortuna, poseían cierto grado de educación.

En Occidente se han aplicado históricamente dos sistemas de sufragio: el censitario y el universal, pero a partir del siglo XX se puede encontrar el universal cualificado. El sistema censitario se empleó en Gran Bretaña hasta la Primera Guerra Mundial y en Chile, hasta 1888. Esto significa que solo tenían tal derecho aquellos nacionales

25 Martínez Sospedra, Marco Marco y Uribe Otarola, Sistemas electorales, 34.

26 Martínez Sospedra, Marco Marco y Uribe Otarola, Sistemas electorales, 33 y ss. 
con determinado estatus económico. Para evitar tal marginación, surgió el sistema de sufragio universal, con unas características especiales: una determinada edad, capacidad de obrar y que no se le haya retirado ese derecho por sus actos delictivos. Todos los votos tienen el mismo valor. El tercer sistema —el universal cualificado-:

Es el único de derecho natural, pues junto con al reconocimiento de modo universal del derecho de sufragio a todos quienes se considere capaces de realizar actos políticos, le atribuye a cada ciudadano un derecho particular o cuantitativo según su realidad existencial. ${ }^{27}$

\subsubsection{Sufragio activo}

El ius suffragii responde al principio de quod omnes tangit cuando un individuo decide libremente participar, es decir, votar para la elección de sus gobernantes o en los referendos. Es un derecho de carácter individual y de ejercicio colectivo. "El derecho de voto es el derecho político fundamental porque garantiza todos los demás derechos". ${ }^{28}$ Esta participación o el sufragio activo es un hito histórico; no es un derecho más, sino la legítima vertiente subjetivada de toda la estructura democrática del Estado. Este derecho fundamental necesita la intervención del Legislador para que establezca los procedimientos y medios para que los ciudadanos puedan ejercerlo.

Se entiende por lo expuesto que el sufragio activo es el derecho a votar y elegir de cada uno de los ciudadanos que sean sus titulares en todas las elecciones que se efectúen. Desde el punto de vista cívico, es un deber de los ciudadanos, como se desprende del propio concepto de soberanía popular.

\subsubsection{Sufragio pasivo}

La legislación electoral ha sido más inflexible a la hora de otorgar el derecho al sufragio pasivo, aunque desde la Segunda Guerra Mundial, hay tendencia a homologar los requisitos. Tras la desaparición de la exigencia de alcanzar un determinado estatus económico (sufragio censitario), en la mayoría de las democracias se requiere la concurrencia de tres condiciones: la edad, la residencia y cualificación profesional. Se trata del ius honorum o el derecho a que cualquier individuo libremente decida presentarse como candidato para ser elegido en los procesos electorales si reúne

27 Tagle Martínez, "El derecho de sufragio o el sufragio ante el derecho", 267.

28 Tribunal Supremo de Estados Unidos. Yick Wo v. Hopkins, 118 U.S. 356, 10 de mayo de 1886. 
los requisitos establecidos en la Ley electoral. No hay que olvidar que existe un vínculo entre el sufragio activo y el sufragio pasivo: "[...] en ningún momento pueden establecer discriminaciones que fomenten la elección de unos candidatos en perjuicio de otros". 29

\subsection{El secreto del sufragio}

Debe ser un derecho inalienable del elector, que ejerce con autonomía, libertad y sin obligación jurídica. El voto secreto significa libertad de elección, se usa en los países democráticos y consiste en que su contenido no sea conocido sin el permiso del elector. De ninguna forma el voto debe ser asociado con un titular concreto.

En el pasado, Mill y el propio Montesquieu defendieron el voto de carácter público. Hoy sería impensable, porque puede resultar coercitivo. El elector nunca debe sentirse coaccionado para ejercer libremente su opción política. Para ello, se habilitan zonas en donde pueda elegir sin sentirse observado. A mitad del siglo XIX, los australianos fueron los pioneros en ejercer el voto secreto.

"El voto es el acto en virtud del cual el ciudadano concurre a la formación de la voluntad colectiva mediante la expresión de su preferencia política de modo formal y público". ${ }^{30}$

\subsection{Formas y efectos del voto}

El voto está orientado a la elección de representantes populares o a responder a la pregunta sometida a la consideración de los ciudadanos en referendo o consulta popular. Todos los países democráticos disponen de normativa acerca de cómo se llevarán a cabo las elecciones.

- Voto directo: se entiende por tal aquel que deposita el ciudadano sin intermediación o delegación, es decir, como persona individual. Se trata de un derecho intransferible y, por consiguiente, no admite intermediarios. Ha de protegerse la libertad del elector para que, al depositar el voto, su orientación corresponda a la voluntad real, sin que haya coacción.

29. Mercedes Iglesias Bárez, Estructura orgánica y derechos fundamentales en la Constitución española de 1978 (Salamanca: Ediciones Universidad de Salamanca, 2010), 266.

30 Martínez Sospedra, Marco Marco y Uribe Otarola, Sistemas electorales, 42 
- Voto indirecto: otros electores eligen a los representantes o al candidato. Se usó al principio del constitucionalismo, por ejemplo, en la Constitución de 1812. Así, se controlaba la participación popular con el control de la elección por élites políticas. Ha de tenerse en cuenta que si los representantes populares no ofrecen rendimientos satisfactorios —en términos de protección de los intereses generales—, provocarán que el propio pueblo reclame formas de democracia directa. En la actualidad se emplea para la elección del presidente de la República en Estados Unidos o de la totalidad o una parte de las cámaras, como el Senado francés o el belga. ${ }^{31}$

— Voto reforzado: puede ser plural y múltiple. El voto plural es el que se concedía al ciudadano como complemento del individual, en virtud de su economía o posición social y cultural. Este sistema de participación se empleó hasta 1918 en Gran Bretaña y a finales del siglo XIX y principios del XX en Bélgica. El voto múltiple consistía en que el titular del derecho lo ejercía en diferentes circunscripciones, según su economía. Las elecciones se celebraban en varias jornadas, con el objeto de que el votante dispusiera de tiempo suficiente para desplazarse.

- Voto por correo: sin duda es una opción para las personas alejadas, ya sea por motivos familiares, profesionales o de vacaciones. Debe estar perfectamente organizado y no vulnerar algún derecho de los ciudadanos, residan o no en ese momento en su país, ciudad, municipio, etc. Es un voto que aún no está muy controlado y se duda de la posible manipulación.

En palabras de Presno Linera:

El derecho fundamental de voto es un derecho subjetivo; es decir, un apoderamiento jurídico (contenido del derecho) que la Constitución atribuye a un sujeto para que pueda defender, asegurar o ejercer determinadas expectativas de participación política (objeto del derecho). Con la fuerza normativa de la Constitución, ese apoderamiento consistirá en la posibilidad de exigir a los poderes públicos que aseguren la intervención de manera directa o a través de representantes en el gobierno político de la comunidad. ${ }^{32}$

La auténtica garantía de un Estado de derecho que merezca ese nombre y de la paz y la seguridad jurídica para los miembros de una comunidad política es que

Martínez Sospedra, Marco Marco y Uribe Otarola, Sistemas electorales, 42-43.

32 Miguel Ángel Presno Linera, "El derecho de voto: un derecho político fundamental" http://presnolinera. wordpress.com/elderechodevotounderechopolíticofundamental.pdf. (acceso diciembre 12, 2016), 10-11. 
se administre justicia a partir de lo que cabe denominar la triple "i": integridad, imparcialidad e independencia.

España y la mayoría de los países iberoamericanos continúan ostentando el menor grado de asociacionismo (incluidos partidos políticos y sindicatos) frente a las muy activas e implicadas sociedades del mundo anglosajón. Con propósito didáctico, se presenta a continuación un cuadro comparativo del reconocimiento y de la regulación constitucional del derecho de sufragio en los ordenamientos jurídicos de Estados iberoamericanos.

En definitiva, como ya opinábamos en otro lado, debe intensificarse el esfuerzo por mejorar la participación en el sistema democrático. Sin participación y sin control constante del ejercicio del poder se produce una muy sensible erosión de la convivencia en libertad. ${ }^{33}$

Sufragio sí y siempre, pero en un clima de información, transparencia, debate libre de ideas, intereses y opiniones y con la irrenunciable vertebración de la ciudadanía mediante el tejido asociativo.

33 José Luis López González y Montserrat de Santiago, "La docencia del derecho constitucional: una perspectiva conceptualista", Prospectiva Jurídica 7, núm. 14 (2016): 97.

En esta misma línea argumentativa de mejora de la calidad de la participación escribe Antonio Colomer Viadel: "Es urgente dignificar el significado de las campañas electorales para evitar [...] ese mercadillo frenético de las campañas electorales, donde con frecuencia se pretende convertir al ciudadano reflexivo en elemento de una masa sugestionable, se realizan las más increíbles ofertas: se otorgan derechos, se declaran principios, pero, a menudo son proclamas como fuegos de artificio que se desvanecen en el aire nada más deslumbrar con la belleza de su estallido", al tiempo que advierte de la perversa concepción de la política "como botín [...] como negocio en donde los vencedores se ven fatalmente como beneficiarios de una expectativa de mejora económica y social. Ciertamente existen los políticos honrados e incluso los héroes incorruptibles, aunque también conocemos los casos frecuentes de enriquecimientos injustificados. Se dan al mismo tiempo formas más sutiles de despreocuparse de ese interés general, por el manejo de esos recursos públicos sin la diligencia y la austeridad que pondríamos en los propios, por no citar las formas más o menos enmascaradas de los viejos clientelismos y nepotismos de antaño". Antonio Colomer Viadel, coord. Regenerar la politica: ciudadanos, ised protagonistas! (Valencia: Ugarit, 2008), 12-13. 
Tabla 1. Derecho comparado del derecho al voto en Estados iberoamericanos

\begin{tabular}{|c|c|c|}
\hline \multicolumn{3}{|c|}{$\begin{array}{l}\text { DERECHO COMPARADO ENTRE PAÍSES IBEROAMERICANOS CON RECONOCIMIENTO DEL DERECHO AL } \\
\text { SUFRAGIO }\end{array}$} \\
\hline Argentina & $\begin{array}{l}\text { Esta Constitución garantiza el pleno ejercicio de los derechos políticos, con arreglo al principio } \\
\text { de la soberanía popular y de las leyes que se dicten en consecuencia. El sufragio es universal, } \\
\text { igual, secreto y obligatorio. }\end{array}$ & Art. 37 \\
\hline Bolivia & $\begin{array}{l}\text { El sufragio, mediante voto igual, universal, directo, individual, secreto, libre y obligatorio, escrutado } \\
\text { públicamente. El sufragio se ejercerá a partir de los dieciocho años cumplidos. }\end{array}$ & Art. 26 \\
\hline Brasil & $\begin{array}{l}\text { La soberanía popular será ejercida por sufragio universal y por voto directo y secreto con valor } \\
\text { igual para todos, y, en los términos de la ley mediante: I plebiscito; II referéndum; III iniciativa } \\
\text { popular. 1. El aislamiento electoral y el voto son: I obligatorios para los mayores de dieciocho } \\
\text { años; II facultativos para: a) Los analfabetos; b) los mayores de setenta años; c) los mayores de } \\
\text { dieciséis años y menores de dieciocho años. }\end{array}$ & Art. 14 \\
\hline Colombia & $\begin{array}{l}\text { El voto es un derecho y un deber ciudadano. El Estado velará porque se ejerza sin ningún tipo } \\
\text { de coacción y en forma secreta por los ciudadanos en cubículos individuales instalados en cada } \\
\text { mesa de votación sin perjuicio del uso de medios electrónicos o informáticos. }\end{array}$ & Art. 258 \\
\hline Costa Rica & $\begin{array}{l}\text { El sufragio es función cívica primordial y obligatoria y se ejerce ante las juntas electorales en } \\
\text { votación directa y secreta, por los ciudadanos inscritos en el registro civil. }\end{array}$ & Art 93 \\
\hline Chile & $\begin{array}{l}\text { En las votaciones populares, el sufragio será personal, igualitario, secreto y voluntario. Sólo } \\
\text { podrá convocarse a votación popular para las elecciones y plebiscitos expresamente previstos } \\
\text { en esta Constitución. }\end{array}$ & Art. 15 \\
\hline Ecuador & $\begin{array}{l}\text { El voto popular será universal, igual, directo y secreto; obligatorio para los que sepan leer y } \\
\text { escribir, facultativo para los analfabetos y para los mayores de sesenta y cinco años. Tendrán } \\
\text { derecho a voto los ecuatorianos que hayan cumplido dieciocho años de edad y se hallen en el } \\
\text { goce de los derechos políticos. }\end{array}$ & Art. 27 \\
\hline El Salvador & $\begin{array}{l}\text { Los derechos políticos de ciudadano son: } 1^{\circ} \text { Ejercer el sufragio } \\
\text { Los deberes políticos del ciudadano son: } 1^{\circ} \text { Ejercer el sufragio }\end{array}$ & $\begin{array}{l}\text { Art. } 72 \\
\text { Art. } 73\end{array}$ \\
\hline Guatemala & $\begin{array}{l}\text { Deberes y derechos políticos. Son derechos y deberes de los ciudadanos: a. Inscribirse en el } \\
\text { Registro de Ciudadanos; b. Elegir y ser electo; c. Velar por la libertad y efectividad del sufragio } \\
\text { y la pureza del proceso electoral. }\end{array}$ & Art. 136 \\
\hline Honduras & $\begin{array}{l}\text { Ejercer el sufragio. } \\
\text { El sufragio es un derecho y una función pública. El voto es universal, obligatorio, igualitario, } \\
\text { directo, libre y secreto. }\end{array}$ & $\begin{array}{l}\text { Art. } 40 \\
\text { Art. } 44\end{array}$ \\
\hline México & Votar en las elecciones populares en los términos que señale la ley. & Art. 36 \\
\hline Panamá & $\begin{array}{l}\text { El sufragio es un derecho y un deber de todos los ciudadanos. El voto es libre, es igual, universal, } \\
\text { secreto y directo. }\end{array}$ & Art. 135 \\
\hline Paraguay & $\begin{array}{l}\text { El sufragio es derecho, deber y función pública del elector. Constituye la base del régimen } \\
\text { democrático y representativo. Se funda en el voto universal, libre, directo, igual y secreto; en el } \\
\text { escrutinio público y fiscalizado, y en el sistema de representación proporcional. }\end{array}$ & Art. 118 \\
\hline Perú & $\begin{array}{l}\text { Es derecho y deber de los vecinos participar en el gobierno municipal de su jurisdicción. La ley } \\
\text { norma y promueve los mecanismos directos e indirectos de su participación. Tienen derecho al } \\
\text { voto los ciudadanos en goce de su capacidad civil. Para el ejercicio de este derecho se requiere } \\
\text { estar inscrito en el registro correspondiente. El voto es personal, igual, libre, secreto y obligatorio } \\
\text { hasta los setenta años. Es facultativo después de esa edad. }\end{array}$ & Art. 31 \\
\hline $\begin{array}{l}\text { República } \\
\text { Dominicana }\end{array}$ & Votar, siempre que se esté en capacidad legal par hacerlo. & Art. 78 \\
\hline Venezuela & $\begin{array}{l}\text { El sufragio es un derecho. Se ejercerá mediante votaciones libres, universales, directas y secretas. } \\
\text { La ley garantizará el principio de la personalización del sufragio y la representación proporcional. }\end{array}$ & Art. 63 \\
\hline
\end{tabular}

Fuente: elaboración propia 


\section{Conclusiones}

El derecho de sufragio es un elemento arquitectural básico de todo el edificio democrático. Es el auténtico instrumento de elección de representantes y la manifestación de pareceres ante una consulta o un referendo. En este sentido, no debe olvidarse que este último, como consulta popular que es, constituye una auténtica actividad electoral, aunque de contenido diferente al propio de la democracia indirecta. El derecho de sufragio se configura, sin duda alguna, como principio básico del ordenamiento democrático.

La catalogación como derecho fundamental del derecho de sufragio no debe ocultar el contenido de deber cívico que acompaña a su ejercicio. Como es lógico, ese contenido adicional de deber cívico en nada afecta a dicha configuración como derecho fundamental dotado de la máxima protección, en la que se incluye la posibilidad de interponer el recurso de amparo.

El derecho de sufragio presenta una evidente trascendencia de cara a la pervivencia del propio sistema institucional derivado de la cláusula constitucional de Estado democrático. La corrupción ha dado lugar, con particular intensidad en el último lustro, a un desaforado (y creo que más que justificado) malestar y a indignación de la ciudadanía, que lamentablemente puede conducir a una preocupante abstención.

En una situación como la que ahora vivimos adquiere más sentido el ejercicio del derecho de sufragio tanto como castigo (a quienes han decepcionado la confianza del pueblo soberano) como en la vertiente constructiva o de ilusión (que apuesta por la renovación democrática mediante el apoyo a las formaciones políticas emergentes). Toda convocatoria de elecciones democráticas se fundamenta en la limitación o el control temporal del ejercicio del poder. El sufragio solo produce auténtica representación cuando es resultado de una decisión meditada del elector. El derecho de sufragio ha de encontrarse unido a un régimen de opinión pública libre. En la actualidad, este requisito no es fácil de cumplir, si se repara en que la titularidad de los medios de comunicación suele pertenecer a instituciones financieras y multinacionales. Tal situación socava hasta extremos intolerables el sistema de libre flujo de ideas y opiniones y deja al ejercicio del derecho de sufragio sin soporte crítico.

En España y en otros países iberoamericanos, el voto electrónico adolece de un desarrollo todavía escaso. Es necesaria una labor pedagógica a escala nacional, en 
la que se dé cuenta de las ventajas de tal sistema (desde las ecológicas hasta las facilidades que puede suponer para votantes con algún tipo de discapacidad).

Debería ampliarse el derecho de sufragio de los extranjeros, como mínimo, a las elecciones autonómicas. En muchos casos, las normas de producción autonómica son las que ofrecen cobertura a las decisiones municipales para las que sí se ha consagrado la participación de extranjeros residentes en un marco de reciprocidad en relación con los españoles. No se olvide que la representación en los Parlamentos y las Asambleas autonómicas no es representación de soberanía, sino una forma de participación democrática a la que deberían tener derecho todos cuantos conviven en el mismo lugar de residencia y pagan impuestos.

No resulta sencillo argumentar la falta de legitimidad de la abstención. Es cierto que la Constitución más antigua de Europa, la de Bélgica, la sanciona administrativamente; sin embargo, del mismo modo que un ciento por ciento de participación no genera perjuicio alguno para la salud de la democracia, la opción opuesta imposibilitaría la continuidad institucional. Ello no hace sino poner de relieve la estrecha conexión, más allá de lo jurídico, entre la participación como deber cívico y el derecho de sufragio. Lo anterior sugiere la necesidad de fomentar la formación para la democracia en principios y valores constitucionales en los planes de estudios de educación primaria y secundaria, unos conocimientos imprescindibles para una convivencia consciente y responsable en libertad.

\section{Referencias}

Aragón Reyes, Manuel y José Luis López González. "Revocatoria de mandato" en Diccionario electoral. San José: Instituto Interamericano de Derechos Humanos, 2000.

Aragón Reyes, Manuel. "Democracia y Parlamento". Revista Catalana de Dret Públic, núm. 37 (2008): 129-155.

Colomer Viadel, Antonio, coord. Regenerar la politica: ciudadanos, ised protagonistas! Valencia: Ugarit, 2008.

García Soriano, María Victoria. Elementos de derecho electoral. Valencia: Tirant lo Blanch, 2010. Herrera Loaiza, Édgar y Enrique Villalobos Quirós. "Sufragio y principio democrático: consideraciones sobre su existencia y vinculancia". Revista de Derecho Electoral, núm. 1 (2006): 1-23.

Iglesias Bárez, Mercedes. Estructura orgánica y derechos fundamentales en la Constitución española de 1978. Salamanca: Ediciones Universidad de Salamanca, 2010.

Kelsen, Hans. Esencia y valor de la democracia. Oviedo: KRK, 2006. 
Kelsen, Hans. Teoría general del Estado. Ciudad de México: Ediciones Coyoacán, 2008. Locke, John. Dos Ensayos sobre el Gobierno Civil. Madrid: Espasa Calpe, 1997.

López González, José Luis y Montserrat de Santiago. "La docencia del derecho constitucional: una perspectiva conceptualista”. Prospectiva Jurídica 7, núm. 14 (2016): 91-118.

López González, José Luis. "El referéndum nacional consultivo sobre decisiones políticas de especial trascendencia en el ordenamiento constitucional español". Revista de Derecho Político, núm. 65 (2006): 233-256.

López González. José Luis. "Lo jurídico y lo político en la respuesta a la crisis institucional: mejora de los instrumentos de supervisión y control y pacto político por el Estado social". Revista Gaceta Sindical. Reflexión y Debate, núm. 23 (2014): 229-242.

Martínez Sospedra, Manuel, Joaquín Marco Marco y Ainhoa Uribe Otarola. Sistemas electorales. Un estudio comparado. Valencia: Tirant Lo Blanch, 2007.

Mendieta Ramírez, Angélica, Enrique González Vallés y David Caldevilla Domínguez. "Pros y contras del voto obligatorio en la formación de la cultura política colectiva: electopartidismo". Perspectivas de la Comunicación 8, núm. 2 (2015): 171-187.

Mill, John Stuart. Consideraciones del gobierno representativo. Madrid: Alianza, 2016.

Montesquieu, Charles. Del espíritu de las leyes. Madrid: Tecnos, 2007.

Presno Linera, Miguel Ángel. "El derecho de voto: un derecho político fundamental". http://presnolinera.wordpress.com/elderechodevotounderechopolíticofundamental. pdf (acceso diciembre 12, 2016).

Real academia de la lengua española. "Sufragio" en Diccionario de la Real Academia Española. http://dle.rae.es/?id=YfDjp3l (acceso diciembre 12, 2016).

Tagle Martínez, Hugo. El derecho de sufragio o el sufragio ante el derecho. Revista Chilena de derecho 6, núm. 1-4 (1979): 265-268.

Tribunal Supremo de Estados Unidos. Yick Wo v. Hopkins, 118 U.S. 356, 10 de mayo de 1886. 